ASTHMA

\title{
Exhaled nitric oxide and asthma: complex interactions between atopy, airway responsiveness, and symptoms in a community population of children
}

\author{
P J Franklin, S W Turner, P N Le Souëf, S M Stick
}

Thorax 2003;58:1048-1052

See end of article for authors' affiliations .....................

Correspondence to: Dr S M Stick, Department of Respiratory Medicine, Princess Margaret Hospital for Children, GPO Box D184, Perth 6001, Australia; sticksm@ cyllene.uwa.edu.au

Received 9 January 2003 Accepted 1 August 2003

\begin{abstract}
Background: Exhaled nitric oxide ( $\mathrm{FE}_{\mathrm{NO}}$ ) is raised in asthmatic children, but there are inconsistencies in the relationship between $\mathrm{FE}_{\mathrm{NO}}$ and characteristics of asthma, including atopy, increased airway responsiveness (AR), and airway inflammation. The aim of this study was to investigate the relationship between $\mathrm{FE}_{\mathrm{NO}}$ and asthma, atopy, and increased AR in children.

Methods: One hundred and fifty five children (79 boys) of mean age 11.5 years underwent an assessment that included $\mathrm{FE}_{\mathrm{NO}}$ measurements, spirometric tests, inhaled histamine challenge, and a skin prick test. Blood was collected for eosinophil count. Current and past asthma like symptoms were determined by questionnaire.

Results: In multiple linear regression analyses $\mathrm{FE}_{\mathrm{NO}}$ was associated with atopy $(p<0.001)$, level of $A R$ $(p=0.005)$, blood eosinophil count $(p=0.007)$, and height $(p=0.002)$ but not with physician diagnosed asthma $(p=0.1)$ or reported wheeze in the last 12 months $(p=0.5)$. Separate regression models were conducted for atopic and non-atopic children and associations between $\mathrm{FE}_{\mathrm{NO}}$ and $\mathrm{AR}$, blood eosinophils and height were only evident in atopic children. Exhaled NO was raised in children with a combination of atopy and increased AR independent of symptoms.

Conclusion: Raised $\mathrm{FE}_{\mathrm{NO}}$ seems to be associated with an underlying mechanism linking atopy and AR but not necessarily respiratory symptoms.
\end{abstract}

$\mathrm{T}$ here is considerable interest in the measurement of fractional exhaled nitric oxide $\left(\mathrm{FE}_{\mathrm{NO}}\right)$, particularly with regard to its potential role in both the diagnosis and management of asthma. ${ }^{1}$ Levels are raised in asthmatic children $^{2}$ and adults, ${ }^{3}$ increase during asthma exacerbations, ${ }^{4}$ and are reduced after corticosteroid treatment. ${ }^{4}$ Exhaled NO is thought to reflect airway inflammation in asthma but only limited data are available regarding the relationship between $\mathrm{FE}_{\mathrm{NO}}$ and any direct evaluation of inflammation such as airway biopsy. ${ }^{56}$ On the other hand, numerous studies have investigated the relationships between $\mathrm{FE}_{\mathrm{NO}}$ and indirect indicators of airway inflammation. For example, $\mathrm{FE}_{\mathrm{NO}}$ is positively correlated with eosinophils in sputum ${ }^{7}$ and lavage fluid. ${ }^{8}$ Furthermore, some studies have reported an association between $\mathrm{FE}_{\mathrm{NO}}$ and airway responsiveness (AR), ${ }^{10}$ but the data regarding the associations between $\mathrm{FE}_{\mathrm{NO}}$ and both eosinophilia ${ }^{56}$ and $\mathrm{AR}^{9-12}$ are inconsistent.

We have previously described associations between atopy and $\mathrm{FE}_{\mathrm{NO}}$ in infants ${ }^{13}$ and children ${ }^{14}$ that are independent of symptoms of asthma. Since our original observations, the importance of taking account of atopy when interpreting $\mathrm{FE}_{\mathrm{NO}}$ measurements has become apparent. Exhaled NO levels are raised in atopic but not in non-atopic asthmatics, ${ }^{11}{ }^{15}$ and our observation that $\mathrm{FE}_{\mathrm{NO}}$ is raised in healthy atopic children has been confirmed in adults. ${ }^{16}$ We believe that inconsistencies in the literature with regard to $\mathrm{FE}_{\mathrm{NO}}$ and indirect markers of inflammation have resulted in part from a failure to fully account for atopy. We therefore hypothesised that atopy modifies the relationships between $\mathrm{FE}_{\mathrm{NO}}$ and important characteristics of asthma (such as AR, eosinophilia, and symptoms). If this is the case, there are important implications with regard to the use of $\mathrm{FE}_{\mathrm{NO}}$ as a diagnostic tool in asthma.

To investigate the association between atopy and $\mathrm{FE}_{\mathrm{NO}}$ in more detail we included $\mathrm{FE}_{\mathrm{NO}}$ measurements in the 11 year follow up of a well characterised birth cohort. This cohort had longitudinal symptom questionnaire data and measurements of lung function, AR, and atopy that allowed accurate phenotypic descriptions with regard to important asthma related characteristics.

\section{METHODS}

Subjects and protocol

Subjects were participants in a prospective birth cohort study of lung function, AR, and atopy that included data from probands and all family members enrolled from an unselected population. ${ }^{17}$ The probands had previously been assessed at 4 weeks, 6 months, 12 months, and 6 years of age. Data for the present study were gathered from the 11 year follow up study. Family members were studied in the first year and at the 6 and 11 year follow up surveys. In the present study 191 of the original cohort of 253 infants and 165 siblings were assessed. All children underwent an assessment that included spirometric tests, inhaled histamine challenge, skin prick testing, and blood eosinophil count. Current and past respiratory symptoms were assessed using a modified ATS questionnaire. ${ }^{18}$ Assessments took place either at the hospital or the child's home. Exhaled NO was measured only in those attending hospital $(n=155,97$ of the original cohort; 58 siblings) and the results from these children are presented in this study. None of the children were symptomatic at the time of the study.

The study was approved by the medical ethics committee of Princess Margaret Hospital for Children. Informed consent was obtained from parents.

\section{Exhaled nitric oxide}

Exhaled NO was measured using a fast response chemiluminescence analyser (NOA 280, Sievers Instruments Inc, Boulder, CO, USA) as previously described. ${ }^{14}$ Measurements 
were taken before spirometry and histamine challenge. Children maintained an expiratory flow of $35 \mathrm{ml} / \mathrm{s}$ and mouth pressure of $15 \mathrm{~cm} \mathrm{H}_{2} \mathrm{O}$.

\section{Pulmonary function and airway responsiveness}

Pulmonary function testing was performed using a hand held spirometer (Pneumocheck Spirometer 6100; Welch-Allyn, Skaneateles Falls, NY, USA) in accordance with published guidelines. ${ }^{19}$ Airway responsiveness to histamine was determined using the rapid dosimeter technique. ${ }^{20}$ Responsiveness was expressed as the dose of histamine $(\mu \mathrm{M})$ that provoked at least a $20 \%$ fall in $\mathrm{FEV}_{1}\left(\mathrm{PD}_{20}\right)$ and increased $\mathrm{AR}$ was defined as $\mathrm{PD}_{20}<7.8 \mu \mathrm{M}$ histamine. ${ }^{21} \mathrm{~A}$ dose response slope (DRS) was also calculated using the method of $\mathrm{O}^{\prime}$ Connor et al. ${ }^{22}$

\section{Skin prick testing and eosinophil count}

Skin reactivity to cow's milk, egg white, rye grass, mixed grass, Dermatophagoides farinae, Dermatophagoides pteronyssinus, cat dander, dog dander, Alternaria alternans and Aspergillus fumigatus (Hollister-Stier, Elkhart, IN, USA) was assessed by skin prick tests as described by Pepys. ${ }^{23}$ The positive control was histamine sulphate $(10 \mathrm{mg} / \mathrm{ml})$ and the negative control was $0.9 \%$ saline. A positive skin prick test was defined as a weal at least $3 \mathrm{~mm}$ in its longest dimension. Atopy was defined as the presence of at least one positive skin prick test.

Blood was collected and the eosinophil count was measured using a flow cytometer (Coulter Maxm, Beckman-Coulter Inc). Values are expressed as absolute cell counts.

\section{Statistical analyses}

Exhaled NO, DRS, and blood eosinophil values were skewed and were $\log _{10}$ transformed before analysis (a constant of 1 was added to DRS values) to achieve a near normal distribution. Associations between $\log \left(\mathrm{FE}_{\mathrm{NO}}\right)$ and reported physician diagnosed asthma, wheeze in the last 12 months (recent wheeze), current asthma (wheeze in the last 12 months plus increased AR), ${ }^{21}$ atopy, $\log$ (DRS), $\log$ (blood eosinophils), height, age, and spirometric variables were assessed in univariate analyses using Student's $t$ tests and simple linear regression. Multiple linear regression analyses were undertaken using transformed $\mathrm{FE}_{\mathrm{NO}}$ values as the outcome variable which was computed by taking the antilog of the estimate of increase (or difference) in transformed $\mathrm{FE}_{\mathrm{NO}}$ to give the fold increase per unit change in a continuous explanatory variable or fold difference between levels of a binary explanatory variable. Only factors that had a significance level of at least $p \leqslant 0.1$ from univariate analyses were included in the model. These were age, height, $\log$ (eosinophil count), $\log$ (DRS), and atopy. Symptoms were included in the model separately as either reported physician diagnosed asthma or recent wheeze. Interactions between atopy and all other factors were investigated and separate regression models were constructed for both atopic and nonatopic children. Variables in all models were excluded in a stepwise fashion if they did not reach significance at the 5\% level. Exhaled NO levels are reported as geometric means (GM) with 95\% confidence intervals (CI). All analyses were performed using SPSS version 9.0 (SPSS, Chicago, IL, USA).

\section{RESULTS}

Exhaled NO concentrations were measured in 155 subjects (79 boys) of mean (SD) age 11.5 (2.3) years (range 6-18). There was no significant difference with regard to age, sex,

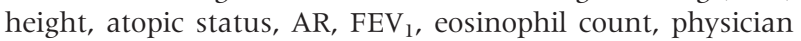
diagnosed asthma, reported recent wheeze, and use of inhaled steroids between these children and those in whom $\mathrm{FE}_{\mathrm{NO}}$ measurements were not made $(\mathrm{n}=201)$.
Five children treated with regular inhaled corticosteroids (ICS) were excluded from analyses because of the known effects of ICS on $\mathrm{FE}_{\mathrm{NO}}$. Of the remaining 150 children, spirometric tests were performed in all individuals, skin prick testing in 149 (99\%), bronchial challenge in 144 (96\%), and eosinophil counts in 136 (91\%). Eighty three children (56\%) were atopic, 54 (38\%) had increased AR, 34 (23\%) reported wheeze in the past 12 months, and $26(17 \%)$ had physician diagnosed asthma.

In univariate analyses, $\mathrm{FE}_{\mathrm{NO}}$ was higher in children who had reported physician diagnosed asthma (16.4 ppb, 95\% CI 11.0 to 24.6$)$ than in non-asthmatic children (11.0 ppb, 95\% CI 9.4 to $12.9 ; \mathrm{p}<0.03)$, in those with reported recent wheeze (16.6 ppb, 95\% CI 11.9 to 23.2) than in those without recent wheeze ( $10.8 \mathrm{ppb}, 95 \%$ CI 9.2 to $12.7 ; \mathrm{p}=0.01)$, and in those with current asthma (24.5 ppb, 95\% CI 15.0 to 40.0 ) than in those without current asthma (11.0 ppb, 95\% CI 9.5 to 12.8 ; $\mathrm{p}<0.001)$. Atopic children (17.9 ppb, 95\% CI 14.9 to 21.4 ) had significantly higher $\mathrm{FE}_{\mathrm{NO}}$ levels than non-atopic children (7.2 ppb, 95\% CI 6.0 to $8.7 ; \mathrm{p}<0.001$ ) and there was a positive correlation between the number of skin prick reactions and $\mathrm{FE}_{\mathrm{NO}}$ (Pearson's correlation coefficient $r=0.61, \mathrm{p}<0.001$ ). There was a positive association between $\mathrm{FE}_{\mathrm{NO}}$ and DRS $\left(r^{2}=0.21, \mathrm{p}<0.001\right)$, eosinophil count $\left(r^{2}=0.11, \mathrm{p}<0.001\right)$, and height $\left(r^{2}=0.05, \mathrm{p}<0.008\right)$. There were no associations between $\mathrm{FE}_{\mathrm{NO}}$ and measurements of pulmonary function when adjusted for height. The relationship between $\mathrm{FE}_{\mathrm{NO}}$ and DRS in atopic and non-atopic children is shown in fig 1.

In the multiple regression model atopy $(\mathrm{p}<0.001)$, DRS $(p=0.003)$, eosinophil count $(p=0.003)$, and height $(p=0.002)$ were all significantly associated with $F_{N O}$ (table 1). Neither physician diagnosed asthma $(p=0.1)$ nor recent wheeze $(p=0.5)$ were associated with $\mathrm{FE}_{\mathrm{NO}}$ in this model. There was a significant interaction between atopy and DRS $(p=0.001)$ and a trend for an interaction between atopy and eosinophil count $(p=0.06)$. In order to examine these interactions further, separate regression models were constructed for atopic and non-atopic children. In these models DRS, eosinophils, and height were associated with $\mathrm{FE}_{\mathrm{NO}}$ in atopic (table 2) but not in non-atopic children (table 3 ). Again, neither physician diagnosed asthma nor recent wheeze were associated with $\mathrm{FE}_{\mathrm{NO}}$ in either of these models.

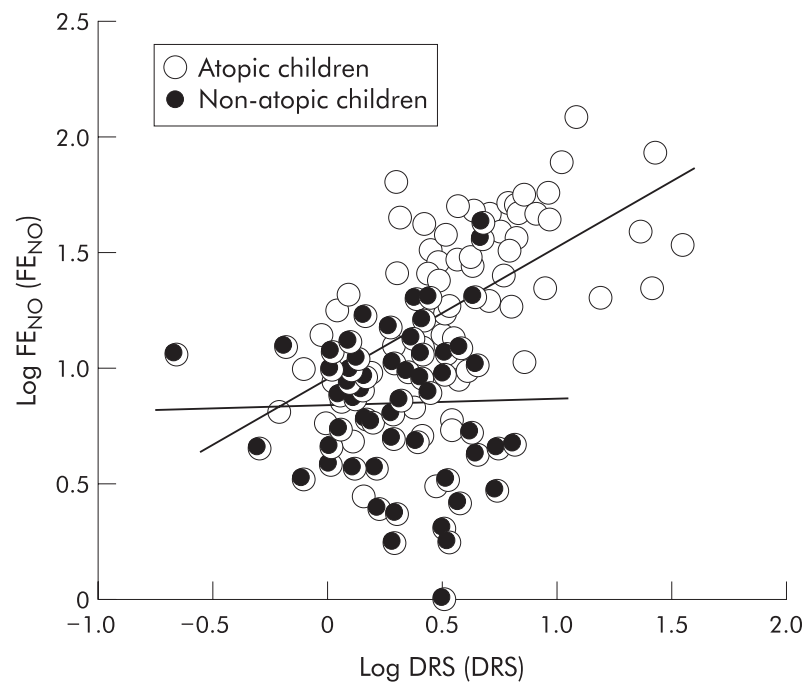

Figure 1 Relationship between $\mathrm{FE}_{\mathrm{NO}}$ and airway responsiveness (DRS) in atopic $(O)$ and non-atopic $(\bullet)$ children. Separate regression lines for atopic and non-atopic children are included. Only in atopic children is there a significant relationship between $\mathrm{FE}_{\mathrm{NO}}$ and DRS $\left(r^{2}=0.301\right.$, $\mathrm{p}<0.001$ ). 
Table 1 Fold difference in fractional exhaled nitric oxide $\left(\mathrm{FE}_{\mathrm{NO}}\right)$ in children with symptoms compared with children without symptoms, and fold increase per unit change in $\log ($ eosinophils), $\log (\mathrm{DRS})$, and height in study population $(n=150)$

\begin{tabular}{llll}
\hline Variable & Fold difference/increase & $95 \% \mathrm{Cl}$ & p value \\
\hline Atopy & 1.83 & 1.39 to 2.41 & $<0.001$ \\
PDA & 1.36 & 0.94 to 1.95 & 0.10 \\
Recent wheeze & 1.10 & 0.81 to 1.51 & 0.53 \\
Eosinophils (per log unit) & 1.94 & 1.26 to 3.00 & 0.003 \\
DRS (per log unit) & 1.88 & 1.25 to 2.86 & 0.003 \\
Height (per cm) & 1.02 & 1.01 to 1.03 & 0.002 \\
\hline PDA = physician diagnosed asthma; DRS = dose response slope. & &
\end{tabular}

As there were a number of sibling pairs in this cohort, there may be genetic linkage within the group. The children from the original cohort $(n=97)$ were therefore analysed separately and the observed associations persisted.

\section{Receiver operator characteristics curve}

As $\mathrm{FE}_{\mathrm{NO}}$ was found to be associated with AR only in atopic children and was independent of symptoms, we hypothesised that $\mathrm{FE}_{\mathrm{NO}}$ may provide a simple test to identify atopic children with increased AR. This was investigated by generating a receiver operator characteristic (ROC) curve to determine the specificity and sensitivity of $\mathrm{FE}_{\mathrm{NO}}$ for predicting increased AR in atopic children (fig 2). For this analysis, increased $\mathrm{AR}$ was defined as $\mathrm{PD}_{20}<7.8 \mu \mathrm{M}^{21}$ A level of $18.4 \mathrm{ppb}$ was identified as giving the best combination of sensitivity and specificity (81.1\% and 78.6\%). The likelihood ratio for an atopic child in our population having $\mathrm{FE}_{\mathrm{NO}}$ of $<18.4 \mathrm{ppb}$ and increased AR is only 0.23. Height, which was associated with $\mathrm{FE}_{\mathrm{NO}}$ in this study, contributed to the variability of the sensitivity and specificity such that individuals below the average height tend to reduce the sensitivity and individuals with above average height tend to reduce the specificity.

\section{DISCUSSION}

This study has shown that atopy modifies the associations between $\mathrm{FE}_{\mathrm{NO}}$ and both $\mathrm{AR}$ and blood eosinophil counts. An important finding is that $\mathrm{FE}_{\mathrm{NO}}$ is raised in children with a combination of both atopy and increased $\mathrm{AR}$, and this was independent of symptoms. Interestingly, $\mathrm{FE}_{\mathrm{NO}}$ was not raised in subjects with only atopy or increased $\mathrm{AR}$. These data suggest that raised $\mathrm{FE}_{\mathrm{NO}}$ levels are the result of a mechanism(s) linking increased AR and atopy and extend the recently published observations of Steerenberg et al. ${ }^{24}$

We have previously reported an association between raised $\mathrm{FE}_{\mathrm{NO}}$ and positive skin prick reactions in healthy children. ${ }^{14}$ The association between increased $\mathrm{FE}_{\mathrm{NO}}$ and atopy in healthy subjects has been confirmed in other studies, ${ }^{16}$ but it is not a universal finding. ${ }^{25}$ Similarly, the data regarding the association between $\mathrm{FE}_{\mathrm{NO}}$ and $\mathrm{AR}$ have been inconclusive. ${ }^{9-12}$ The results of this study extend our earlier observations and help to explain some inconsistencies in reported data. Our observations also explain the consistent reports of raised $\mathrm{FE}_{\mathrm{NO}}$ levels in atopic compared with non-atopic asthmatics. ${ }^{11}{ }^{15}$

A major finding from both our study and a recent study by Steerenberg et $\mathrm{l}^{24}$ is that the relationship between $\mathrm{FE}_{\mathrm{NO}}$ and AR is only evident in atopic children. Ludviksdottir and colleagues $^{15}$ reported a similar relationship in asthmatic adults. There is a well established relationship between atopy and increased AR in both children ${ }^{26}{ }^{27}$ and adults, ${ }^{27}$ and our data suggest that increased NO production in the airways may be associated with a mechanism linking these two factors. This may involve inflammatory processes and would support the hypothesis that $\mathrm{FE}_{\mathrm{NO}}$ is a marker of allergic airway inflammation. Peat et al ${ }^{28}$ suggested that IgE mediated inflammatory reactions in the airways of atopic children could lead to increased AR. We found that there was a relationship between $\mathrm{FE}_{\mathrm{NO}}$ and blood eosinophils which was also dependent on the presence of atopy. This relationship has also been reported in an unselected population of children, ${ }^{24}$ as well as in a group of asthmatic children. ${ }^{29}$ In our study there was a positive correlation between peripheral eosinophils and DRS in the atopic but not the non-atopic children (data not shown). Blood eosinophils, however, do not necessarily reflect inflammatory processes in the lungs, ${ }^{30}$ and an alternative explanation is that increased $\mathrm{FE}_{\mathrm{NO}}$ in this phenotype may be due to genetic variations in NO synthase (NOS) genes. In patients with asthma ${ }^{31}$ and cystic fibrosis, ${ }^{32}$ variations in $\mathrm{FE}_{\mathrm{NO}}$ are associated with a polymorphism in the NOS1 gene. The NOS1 isoform has been shown to be important in the regulation of AR in animal models. ${ }^{33}$ Further investigations are required to determine the contribution of the various NOS isoform(s) to NO production in the airways of children with atopy and increased AR.

Interestingly, we found that the association between $\mathrm{FE}_{\mathrm{NO}}$ and atopy and increased AR was independent of symptoms. This was a representative population sample of asthmatic children, although children with more severe asthma (those taking ICS) were excluded because of the known effects of ICS on $\mathrm{FE}_{\mathrm{NO}}$. Our findings are in agreement with those of Leuppi et $a l^{34}$ who found significantly raised $\mathrm{FE}_{\mathrm{NO}}$ levels in

Table 2 Fold difference in fractional exhaled nitric oxide $\left(\mathrm{FE}_{\mathrm{NO}}\right)$ in children with symptoms compared with children without symptoms, and fold increase per unit change in $\log ($ eosinophils), $\log (D R S)$, and height in atopic children $(n=80)$

\begin{tabular}{llll}
\hline Variable & Fold difference/increase & $\mathbf{9 5 \%} \mathbf{C l}$ & p value \\
\hline PDA & 1.18 & 0.79 to 1.75 & 0.40 \\
Recent wheeze & 1.09 & 0.76 to 1.57 & 0.62 \\
Eosinophils (per log unit) & 2.24 & 1.22 to 4.06 & 0.01 \\
DRS (per log unit) & 2.38 & 1.46 to 3.94 & 0.001 \\
Height (per cm) & 1.015 & 1.003 to 1.03 & 0.017 \\
\hline
\end{tabular}

PDA = physician diagnosed asthma; DRS = dose response slope. 
Table 3 Fold difference in fractional exhaled nitric oxide $\left(\mathrm{FE}_{\mathrm{NO}}\right)$ in children with symptoms compared with children without symptoms, and fold increase per unit change in $\log ($ eosinophils), $\log (\mathrm{DRS})$, and height in non-atopic children $(n=70)$

\begin{tabular}{llll}
\hline Variable & Fold difference/increase & $95 \% \mathbf{C l}$ & $\mathbf{p}$ value \\
\hline PDA & 1.95 & 0.82 to 4.48 & 0.13 \\
Recent wheeze & 1.04 & 0.57 to 1.90 & 0.14 \\
Eosinophils (per log unit) & 1.52 & 0.81 to 2.86 & 0.19 \\
DRS (per log unit) & 0.92 & 0.41 to 2.07 & 0.84 \\
Height (per cm) & 1.00 & 0.99 to 1.03 & 0.15 \\
\hline
\end{tabular}

PDA = physician diagnosed asthma; $\mathrm{DRS}=$ dose response slope.

atopic children with increased AR, regardless of symptoms. These authors suggested that $\mathrm{FE}_{\mathrm{NO}}$ may be more closely associated with increased AR than symptoms. In contrast, Henriksen et al ${ }^{10}$ found that suspected asthmatic adolescents with both atopy and increased AR had higher $\mathrm{FE}_{\mathrm{NO}}$ levels than healthy subjects with a similar phenotype. Similarly, Steerenberg et $a^{24}$ found that $\mathrm{FE}_{\mathrm{NO}}$ was associated with respiratory symptoms in atopic children, but it appears that these authors might not have controlled for AR when investigating the association between $\mathrm{FE}_{\mathrm{NO}}$ and symptoms. Our results, if confirmed in future studies, suggest that raised $\mathrm{FE}_{\mathrm{NO}}$ levels in children are associated with a common asthma phenotype (that is, atopy and increased AR) but not with asthma per se.

Our observation that $\mathrm{FE}_{\mathrm{NO}}$ is raised in healthy children with both atopy and increased AR raises an intriguing possibility that NO might be protective in these children who are at risk of asthma but who have not developed symptoms. Indeed, there have been suggestions that NO may have a bronchoprotective role through its actions on smooth muscle relaxation and inhibition of smooth muscle proliferation. ${ }^{35}$ Alternatively, raised $\mathrm{FE}_{\mathrm{NO}}$ may identify children who have latent asthma and are at risk of developing symptoms. Both atopy and increased AR in childhood have been reported as risk factors for the subsequent development of asthma in early adulthood. ${ }^{36}$ However, atopy and increased AR can coexist in adults in the absence of symptoms. ${ }^{27}$ The association between raised $\mathrm{FE}_{\mathrm{NO}}$ levels and the development of asthma later in life can only be addressed by longitudinal data. This cohort will be reassessed 5 years after the present data were obtained.

There has been considerable interest in $\mathrm{FE}_{\mathrm{NO}}$ as a diagnostic tool for asthma. A number of studies have reported good sensitivity and specificity of raised $\mathrm{FE}_{\mathrm{NO}}$ for discriminating between asthmatics and non-asthmatics. ${ }^{37-39}$ In each of these studies the asthmatic patients had increased

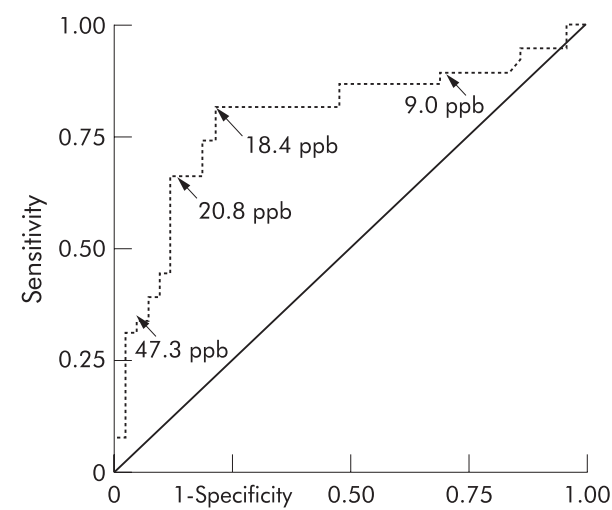

Figure 2 ROC curve indicating the sensitivity and specificity for predicting increased AR in atopic children. Sensitivity and specificity were $81.1 \%$ and $78.6 \%$, respectively, for an $\mathrm{FE}_{\mathrm{NO}}$ level of $18.4 \mathrm{ppb}$.
AR or significant airways reversibility while the nonasthmatics all responded normally. No study has investigated the diagnostic value of $\mathrm{FE}_{\mathrm{NO}}$ in an unselected population. On the basis of our results we propose that low levels of $\mathrm{FE}_{\mathrm{NO}}$ may be useful to exclude increased AR in atopic children with symptoms and, therefore, to help to exclude a diagnosis of asthma. Increased AR is almost ubiquitous in clinically obvious asthma and most asthmatic children are atopic. ${ }^{21}$ Tests of AR are not feasible in most clinical situations, particularly in children. Our data suggest that atopic children with respiratory symptoms but low $\mathrm{FE}_{\mathrm{NO}}$ levels are unlikely to have increased AR. Indeed, in our study, if $\mathrm{FE}_{\mathrm{NO}}$ levels are less than $18.4 \mathrm{ppb}$, the likelihood ratio for atopic children to have increased AR is only 0.23. We suggest that the diagnostic value of low $\mathrm{FE}_{\mathrm{NO}}$ levels could be further tested in a prospective study.

We have used an expiratory flow rate of $35 \mathrm{ml} / \mathrm{s}$ for measuring $\mathrm{FE}_{\mathrm{NO}}$. The study was started before publication of recommendations for the measurement of $\mathrm{FE}_{\mathrm{NO}}$ in children. ${ }^{40}$ However, the marginally lower expiratory flow rate than that suggested in these guidelines used in our study is unlikely to affect our findings since Kissoon et $a l^{41}$ have reported that flow rates between 30 and $50 \mathrm{ml} / \mathrm{s}$ are appropriate for children. Indeed, the use of a low flow rate may have increased our ability to measure differences in $\mathrm{FE}_{\mathrm{NO}}$ between groups. Deykin et $a^{38}$ showed in adults using higher flow rates that the discriminatory power of $\mathrm{FE}_{\mathrm{NO}}$ for differentiating between asthmatic and non-asthmatic subjects was not affected by expiratory flow rates ranging from $47 \mathrm{ml} / \mathrm{s}$ to $500 \mathrm{ml} / \mathrm{s}$.

In summary, we have shown that atopy is important in the relationship between $\mathrm{FE}_{\mathrm{NO}}$ and $\mathrm{AR}$. In this study, $\mathrm{FE}_{\mathrm{NO}}$ was associated with increased AR only in atopic children. Furthermore, there was an association between $\mathrm{FE}_{\mathrm{NO}}$ and blood eosinophils that was also only evident in atopic children. This supports the concept that $\mathrm{FE}_{\mathrm{NO}}$ reflects allergic airway inflammation and this may be one of the mechanisms explaining the relationship between atopy and AR. Alternatively, raised $\mathrm{FE}_{\mathrm{NO}}$ levels in children with both atopy and increased AR may be due to variations in NOS genes. This needs to be explored further. Raised $\mathrm{FE}_{\mathrm{NO}}$ levels in non-asthmatic atopic children with increased AR may either be predictive for the development of asthma or may indicate a protective role of NO against the develop ment of symptoms. These issues will be addressed in the next follow up study of this population of children. After controlling for both atopy and increased AR, we were unable to show an association between $\mathrm{FE}_{\mathrm{NO}}$ and asthma or asthma like symptoms. This suggests that raised $\mathrm{FE}_{\mathrm{NO}}$ levels in children are associated with a common asthma phenotype but not with asthma per se. These results have implications for the use of $\mathrm{FE}_{\mathrm{NO}}$ as a diagnostic tool for asthma. However, we have proposed a role for $\mathrm{FE}_{\mathrm{NO}}$ in atopic children with symptoms of unknown aetiology to exclude increased AR and, by inference, to help to exclude asthma. 


\section{ACKNOWLEDGEMENTS}

The authors would like to express their gratitude to study members and their parents for participating in this project.

\section{Authors' affiliations}

P J Franklin, S W Turner, S M Stick, Department of Respiratory Medicine, Princess Margaret Hospital for Children, Perth, Australia P J Franklin, S W Turner, P N Le Souëf, University Department of Paediatrics, Princess Margaret Hospital for Children, Perth, Australia

Dr Turner was supported by the NH\&MRC. Dr Franklin and Dr Stick are supported by the NH\&MRC.

\section{REFERENCES}

1 Kharitonov SA, Barnes PJ. Clinical aspects of exhaled nitric oxide. Eur Respir J 2000; 16:781-92.

2 Artlich A, Hagenah JU, Jonas S, et al. Exhaled nitric oxide in childhood asthma. Eur J Pediatr 1996; 155:698-701.

3 Alving K, Weitzberg E, Lundberg JM. Increased amount of nitric oxide in exhaled air of asthmatics. Eur Respir J 1993;6:1368-70.

4 Baraldi E, Azzolin NM, Zanconato S, et al. Corticosteroids decrease exhaled nitric oxide in children with acute asthma. J Pediatr 1997;131:381-5.

5 Lim S, Jatakanon A, Meah S, et al. Relationship between exhaled nitric oxide and mucosal eosinophilic inflammation in mild to moderately severe asthma. Thorax 2000;55: 184-8.

6 Payne DNR, Adcock IM, Wilson NM, et al. Relationship between exhaled nitric oxide and mucosal eosinophilic inflammation in children with difficult asthma, after treatment with oral prednisolone. Am J Respir Crit Care Med 2001;164:1376-81.

7 Piacentini GL, Bodini A, Costella S, et al. Exhaled nitric oxide and sputum eosinophil markers of inflammation in asthmatic children. Eur Respir J 1999; 13:1386-90.

8 Thomassen MJ, Raychaudhuri B, Dweik RA, et al. Nitric oxide regulation of asthmatic airway inflammation with segmental allergen challenge. J Allergy Clin Immunol 1999; 104:1174-82.

9 Dupont LJ, Rochette F, Demedts MG, et al. Exhaled nitric oxide correlates with airway hyperresponsiveness in steroid-naive patients with mild asthma. Am J Respir Crit Care Med 1998;157:894-8.

10 Henriksen AH, Lingaas-Holmen T, Sue-Chu M, et al. Combined use of exhaled nitric oxide and airway hyperresponsiveness in characterizing asthma in a large population survey. Eur Respir J 2000;15:849-55

11 Ho LP, Wood FT, Robson A, et al. Atopy influences exhaled nitric oxide levels in adult asthmatics. Chest 2000:118:1327-31.

12 Silvestri M, Spallarossa D, Battistini E, et al. Dissociation between exhaled nitric oxide and hyperresponsiveness in children with mild intermittent asthma. Thorax 2000:55:484-8.

13 Wildhaber JH, Hall GL, Stick SM. Measurements of exhaled nitric oxide with the single-breath technique and positive expiratory pressure in infants. Am J Respir Crit Care Med 1999;159:74-8.

14 Franklin PJ, Taplin R, Stick SM. A community study of exhaled nitric oxide in healthy children. Am J Respir Crit Care Med 1999:159:69-73.

15 Ludviksdottir D, Janson C, Hogman M, et al. Exhaled nitric oxide and its relationship to airway responsiveness and atopy in asthma. BHR Study Group. Respir Med 1999;93:552-6.

16 Salome CM, Roberts AM, Brown NJ, et al. Exhaled nitric oxide measurements in a population sample of young adults. Am J Respir Crit Care Med 1999; 159:911-6

17 Young S, Le Souëf PN, Geelhoed GC, et al. The influence of a family history of asthma and parental smoking on airway responsiveness in early infancy. N Engl J Med 1991;324:1168-73.
18 Ferris BG. Epidemiology Standardization Project (American Thoracic Society). Am Rev Respir Dis 1978;118:1-120.

19 Gardner RM, Hankinson JL, Clausen JL, et al. Standardization of spirometry1987 update. Statement of the American Thoracic Society. Am Rev Respir Dis 1987:136:1285-98.

20 Yan K, Salome C, Woolcock AJ. Rapid method for measurement of bronchial responsiveness. Thorax 1983;38:760-5.

21 Toelle BG, Peat JK, Salome CM, et al. Toward a definition of asthma for epidemiology. Am Rev Respir Dis 1992;146:633-7.

22 O'Connor G, Sparrow D, Taylor D, et al. Analysis of dose-response curves to methacholine. An approach suitable for population studies. Am Rev Respir Dis 1987; 136:1412-7.

23 Pepys J. Skin tests for immediate, type I, allergic reactions. Proc $R$ Soc Med 1972;65:271-2.

24 Steerenberg PA, Janssen NA, de Meer G, et al. Relationship between exhaled $\mathrm{NO}$, respiratory symptoms, lung function, bronchial hyperresponsiveness, and blood eosinophilia in school children. Thorax 2003;58:242-5.

25 Frank TL, Adisesh A, Pickering AC, et al. Relationship between exhaled nitric oxide and childhood asthma. Am J Respir Crit Care Med 1998:158:1032-6.

26 Sears MR, Burrows B, Herbison GP, et al. Atopy in childhood. III. Relationship with pulmonary function and airway responsiveness. Clin Exp Allergy 1993:23:957-63.

27 Peat JK, Toelle BG. Dermand J, et al. Serum IgE levels, atopy, and asthma in young adults: results from a longitudinal cohort study. Allergy 1996:51:804-10.

28 Peat JK, Salome CM, Woolcock AJ. Longitudinal changes in atopy during a 4year period: relation to bronchial hyperresponsiveness and respiratory symptoms in a population sample of Australian schoolchildren. J Allergy Clin Immunol 1990:85:65-74.

29 Silvestri M, Sabatini F, Sale R, et al. Correlations between exhaled nitric oxide levels, blood eosinophilia, and airway obstruction reversibility in childhood asthma are detectable only in atopic individuals. Pediatr Pulmonol $2003 \cdot 35 \cdot 358-63$

30 Fabbri LM, Durham S, Holgate ST, et al. Assessment of airway inflammation: an overview. Eur Respir J 1998;26(Suppl):6S-8S.

31 Wechsler ME, Grasemann H, Deykin A, et al. Exhaled nitric oxide in patients with asthma: association with NOS1 genotype. Am J Respir Crit Care Med 2000; 162:2043-7.

32 Grasemann H, Knauer N, Buscher R, et al. Airway nitric oxide levels in cystic fibrosis patients are related to a polymorphism in the neuronal nitric oxide synthase gene. Am J Respir Crit Care Med 2000;162:2172-6.

33 Tulic MK, Wale JL, Holt PG, et al. Differential effects of nitric oxide synthase inhibitors in an in vivo allergic rat model. Eur Respir J 2000;15:870-7.

34 Leuppi JD, Downs SH, Downie SR, et al. Exhaled nitric oxide levels in atopic children: relation to specific allergic sensitisation, AHR, and respiratory symptoms. Thorax 2002:57:518-23.

35 Ricciardolo FL. Multiple roles of nitric oxide in the airways. Thorax 2003;58:175-82

36 Peat JK, Toelle BG, Mellis CM. Problems and possibilities in understanding the natural history of asthma. J Allergy Clin Immunol 2000;106/Suppl 3):S144-52.

37 Avital A, Uwyyed K, Berkman N, et al. Exhaled nitric oxide and asthma in young children. Pediatr Pulmonol 2001;32:308-13.

38 Deykin A, Massaro AF, Drazen JM, et al. Exhaled nitric oxide as a diagnostic test for asthma: online versus offline techniques and effect of flow rate. Am J Respir Crit Care Med 2002;165:1597-601.

39 Dupont L, Demedts MG, Verleden GM. Prospective evaluation of the validity of exhaled nitric oxide for the diagnosis of asthma. Chest 2003;123:751-6.

40 American Thoracic Society. Recommendations for standardized procedures for the online and offline measurement of exhaled lower respiratory nitric oxide and nasal nitric oxide in adults and children - 1999. Am J Respir Crit Care Med 1999;160:2104-17.

41 Kissoon N, Duckworth $\sqcup$, Blake KV, et al. FE(NO): relationship to exhalation rates and online versus bag collection in healthy adolescents. Am J Respir Crit Care Med 2000;162:539-45. 